\title{
MANAGEMENT OF ENDOCRINE DISEASE Isolated maternal hypothyroxinemia during pregnancy: knowns and unknowns
}

\author{
Chrysoula Dosiou' ${ }^{1}$ and Marco Medici ${ }^{2}$ \\ 'Division of Endocrinology, Stanford University School of Medicine, Stanford, California, USA and \\ 2Department of Endocrinology and Rotterdam Thyroid Center, Erasmus Medical Center, Rotterdam, \\ The Netherlands
}

\author{
Correspondence \\ should be addressed \\ to C Dosiou or M Medici \\ Email \\ cdosiou@stanford.edu or \\ m.medici@erasmusmc.nl
}

\begin{abstract}
Isolated maternal hypothyroxinemia (IMH) during pregnancy is defined as a low maternal $\mathrm{T}_{4}$ in the absence of TSH elevation. As IMH is common, with a prevalence of $1-2 \%$ in iodine-sufficient populations, and early research has suggested adverse effects on fetal neurodevelopment, it has been the focus of many studies in the last decade. In the current review, we first discuss the significance of IMH based on data from animal models and recent discoveries regarding the role of thyroid hormone on neurodevelopment. We address issues surrounding the definition and prevalence of this entity and discuss new insights into the etiologies, clinical consequences and management of IMH. A number of large cohort studies have investigated the effects of IMH on the risk of various pregnancy complications and child neurodevelopment. We review these studies in detail and describe their limitations. We discuss the available research on management of $\mathrm{IMH}$, including two recent randomized controlled trials (RCTs). Finally, we delineate the remaining uncertainties in this field and emphasize the need for a sufficiently powered, placebo-controlled RCT on the treatment of IMH early in the first trimester of pregnancy.

\section{Introduction}

Thyroid hormone (TH) is critical for normal fetal development. The importance of TH in neurodevelopment is illustrated by conditions in which there is significant deprivation of neurons from this hormone. Severe iodine deficiency or mutations of the MCT8 thyroid hormone transporter in the brain are two such conditions that cause severe mental retardation. The significance of milder decreases of $\mathrm{TH}$ levels, however, remains unclear. Specifically, the entity of isolated maternal

hypothyroxinemia (IMH), which is the presence of low maternal $\mathrm{T}_{4}$ in the absence of TSH elevation, has in recent years been the focus of increasing interest. Despite the fact that $\mathrm{IMH}$ is prevalent $(1-2 \%$ of pregnant women in iodine-sufficient populations), and a number of studies in the last decade have shown associations with adverse neurodevelopmental outcomes, its causes as well as potential consequences have not yet been fully elucidated. The goal of this review is to summarize what is
\end{abstract}

\section{Invited Author's profile}

Marco Medici, MD, PhD, MSc, is a clinical endocrinologist at the Erasmus Medical Center in Rotterdam, the Netherlands. His principal areas of research include the effects of thyroid dysfunction during pregnancy. He is also the PI of an international consortium investigating the genetic determinants of the Hypothalamus-PituitaryThyroid axis.

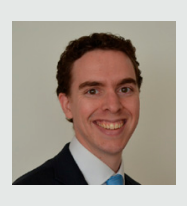

() 2017 European Society of Endocrinology Printed in Great Britain
Published by Bioscientifica Ltd. 
known regarding the epidemiology, causes, adverse effects and treatment of IMH, while also highlighting the areas of remaining uncertainty regarding this condition. We will first shortly review the changes in TH physiology in normal pregnancy, the role of TH in neurodevelopment and the various methods of $\mathrm{T}_{4}$ measurement, as these topics are essential in the understanding of the remaining uncertainties in the field.

\section{Background and significance}

\section{Thyroid physiology during pregnancy}

The demands on the maternal thyroid significantly increase during pregnancy, through a number of mechanisms. Human chorionic gonadotropin (HCG) secreted by the placenta directly stimulates the TSH receptor, increasing TH production $(1,2)$. This results in a small transient increase in $\mathrm{FT}_{4}$ with a reciprocal drop in TSH in the first trimester $(1,2)$. As thyroid-binding globulin synthesis increases 2.5 -fold under the influence of estrogen (2), more TH production is needed to maintain adequate $\mathrm{FT}_{4}$ levels. Thyroxine metabolism also increases, due to placental deiodinase activity, contributing to the need for increased TH production (2). Finally, there is increased renal clearance of iodine (3), which is a key element of TH. In order to meet the need for increased TH levels during pregnancy, the thyroid boosts its production by approximately $50 \%$. In order for the maternal thyroid to successfully achieve this increase, it needs to have adequate iodine supply and also not suffer from significant underlying autoimmunity.

\section{Thyroid hormone and fetal brain development}

The main TH needed for fetal neurodevelopment is $T_{4}$. $\mathrm{T}_{4}$ enters the fetal brain, where it is converted by local deiodinases to $T_{3}$, which then acts on local thyroid receptors to affect different aspects of neurodevelopment (4). Fetal thyroid function in humans starts at 18-22 weeks gestation (16-20 weeks after conception), so before that time, the fetus is exclusively dependent on maternal $\mathrm{T}_{4}$. Inadequate supply of maternal $\mathrm{T}_{4}$ to the fetus before the onset of fetal thyroidal maturation can significantly influence processes that occur during that neurodevelopmental window, such as neuronal migration and proliferation. This concept is well supported by animal studies, as described below. It has been suggested that teleologically the HCG-mediated increase in $T_{4}$ production in the first trimester is an evolution of the conceptus to ensure that it will be exposed to adequate $\mathrm{FT}_{4}$ during its critical phase of neurogenesis (5).

During the last three decades, a number of important observations have supported the critical role of thyroid hormone in neurodevelopment. In 1984, Bernal and Pekonen first identified high-affinity nuclear TH receptors (TRs) in the human fetal brain as early as 8 weeks gestation (6). Subsequent studies in the next two decades identified $\mathrm{T}_{4}$ in coelomic fluid at 6 weeks gestation (7) and further described the details of TRs and deiodinase activity in early fetal brain $(8,9,10)$. In more recent years, multiple $\mathrm{TH}$ responsive genes have been identified $(11,12)$, including genes involved in differentiation, migration, myelination, axonal growth and synapse formation. Thyroid hormone is believed to play a key role in the processes of neuronal migration in the hippocampus and neocortex, development of cortical connections, cytoskeleton assembly, and neuronal development and maturation.

\section{Animal models of IMH}

Successful animal models of maternal hypothyroxinemia have been developed and have shown that even transient early IMH can cause structural and functional changes in developing brains, which can only be prevented with timely levothyroxine supplementation. Before discussing the relevant animal studies, it is useful to recognize some important differences between human and rat neurodevelopment. The development of the neocortex in humans occurs between the 6th and 24th week of gestation and the main waves of radial migration peak at 11 and 14 weeks gestation (reviewed in 12). In the rat, embryonic day 0 (E0) is the day of conception; birth occurs at E21-E22, while fetal thyroid is functional at E17.5-18. Neurogenesis and migration in the rat occur over 10 days, between E11 and E21, and therefore a period of 3 days in rat brain development corresponds roughly to 37-38 days in humans (13).

Animal studies designed to evaluate effects of IMH in neurodevelopment have used two models of inducing IMH: feeding dams iodine-deficient diets, or exposing dams to 3 days of methimazole causing mild thyroid hormone deficiency.

Lavado-Autric et al. studied cell migration and cytoarchitecture in the somatosensory cortex and hippocampus of 40-day-old progeny of dams fed lowiodine diet. Dams had normal serum $\mathrm{T}_{3}$ but undetectable serum $\mathrm{T}_{4}$ levels, with normal reproductive performance. Aberrant migration of cortical neurons was observed in 
the 40-day-old offspring of mothers fed low-iodine diet; this was also seen in neurons that developed before the onset of fetal thyroid hormone secretion. There was also aberrant cytoarchitecture of the somatosensory cortex and hippocampus in the offspring, with blurred layering and abnormal barrel formation (14).

Ausó et al. (13) treated dams with 3 days of lowdose MMI early in gestation (E12-E15) and compared neurodevelopment and neurologic behavior in offspring of treated animals, controls or animals whose hypothyroidism was adequately treated with $\mathrm{LT}_{4}$ for 3 days starting either 1 day after MMI (E13) or after 3 days (E15). IMH caused abnormalities in migration and cytoarchitecture of the somatosensory cortex and hippocampus. Treatment with $\mathrm{T}_{4}$ could rescue this phenotype if done early (starting day E13) but not late (E15) (Fig. 1). Affected offspring showed abnormal behavior in response to acoustic stimuli with wild runs, followed in some with seizures, which could be prevented with early treatment with thyroid hormone (Fig. 1). This paper has important repercussions for human study design and timing of intervention, as neurogenesis in humans starts at E35-42 (gestational week 7-8), while the equivalent times to the above experimental timepoints would be human gestational week 7 for rat E11, week 10.5 for E13 and week 14 for E15 respectively. One could extrapolate that an intervention aimed to rescue neurodevelopmental repercussions of IMH in humans would be successful before gestational week 10.5 but not at gestational week 14 .

In addition to the aberrant cytoarchitecture seen in the above studies, maternal hypothyroxinemia in animal models has been associated with a number of other structural changes, including limited dendritic growth of cerebellar Purkinje cells (15), delayed hippocampal axonal development (16) and alterations of glutamergic synapses (17). Functional consequences of maternal hypothyroxinemia in the fetus have been impaired spatial learning (17), impairment of long-term potentiation in the hippocampus (17) and increased frequency of abnormal response (wild runs or seizures) to audiogenic stimuli (13). Taken together, the available animal models clearly show detrimental effects of IMH on various aspects of fetal neurodevelopment.

\section{Measurement of maternal $\mathbf{T}_{4}$}

Before defining $\mathrm{IMH}$, it is important to review the caveats associated with $\mathrm{T}_{4}$ measurement in pregnancy. Measurement of maternal $\mathrm{T}_{4}$ is complicated by a number
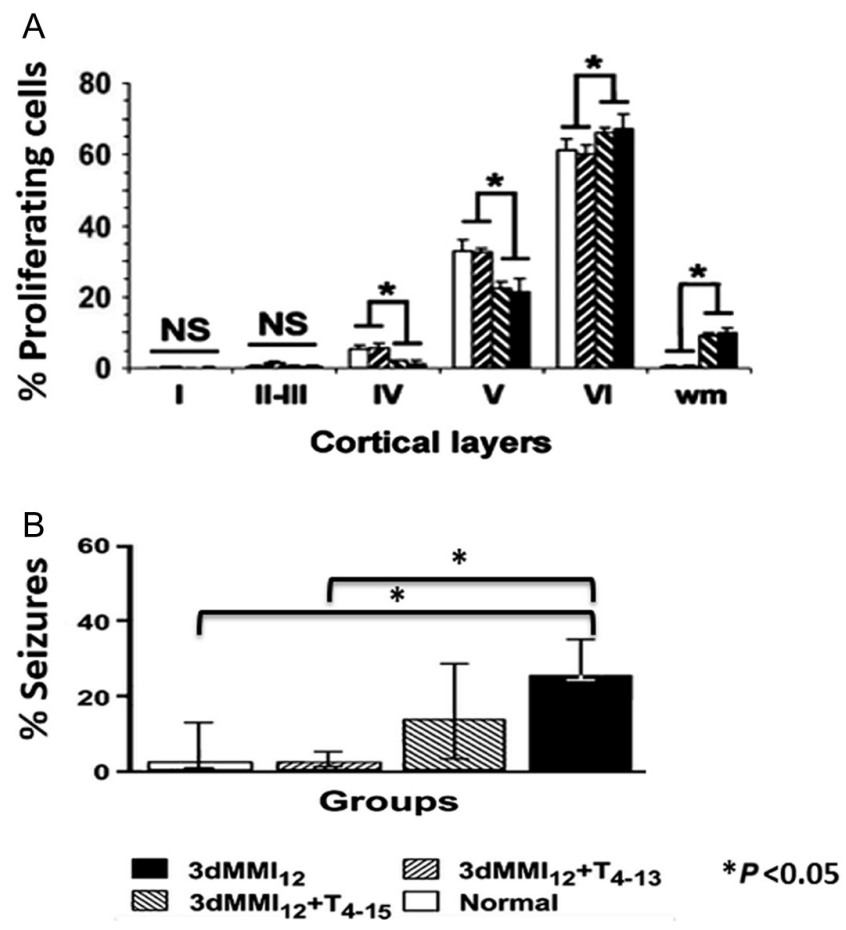

\section{Figure 1}

Effects of early maternal hypothyroxinemia on fetal neurodevelopment. Adapted with permission from Ausó et al. (13). Pregnant rats were divided into four groups: one group of normal dams, one group that took only methimazole for 3 days (3dMMI12), one that took methimazole with the addition of T4 for 3 days, starting one day later, from E13-E16 (3dMMI12 T4-13) and one group that took methimazole with additional T4 starting 3 days later, from E15-E18 (3dMMI12 T4 -15). The onset of the day of treatment is indicated in the subscripts. A. Histograms show quantification of proliferating cells (immunoreactive to BrdU) in different cortical layers of the primary somatosensory cortex of pups born to the above treatment groups. Asterisks indicate a statistically significant difference between pups (normal and 3dMMI12 T4 -13 versus 3dMMI12 T4 -15 and 3dMMI12). B. Responses of normal, 3dMMI12, 3dMMI12 T4-13, and 3dMMI12 T4 -15 pups to an acoustic stimulus. Bars reflect the proportion (median with 25th and 75th percentiles) of pups responding with wild runs followed by a seizure.

of factors. $\mathrm{T}_{4}$ is mostly bound (99.97\%): $60-75 \%$ bound to thyroid-binding globulin (TBG), 16-30\% to transthyretin and $10 \%$ to albumin $(18,19)$. It is the very small free $\mathrm{T}_{4}$ $\left(\mathrm{FT}_{4}\right)$ fraction $(0.03 \%)$ that is responsible for $\mathrm{T}_{4}$ actions and therefore the analyte most frequently used to assess TH levels in nonpregnant patients. In pregnancy, there are a number of changes in the thyroxine-binding proteins 
that affect results of $\mathrm{FT}_{4}$ measurements. TBG levels increase 2.5 -fold, albumin levels decrease and nonesterified fatty acid levels increase. These changes introduce inaccuracies in the $\mathrm{FT}_{4}$ assessment, which can vary depending on the method.

$\mathrm{FT}_{4}$ can be measured either through indirect methods such as immunoassays or through direct methods such as equilibrium dialysis or ultrafiltration that can be followed by liquid chromatography/tandem mass spectrometry. The $\mathrm{FT}_{4}$ immunoassays significantly underestimate $\mathrm{FT}_{4}$, while results vary greatly among the different assays. Sapin et al., in a study using 9 different assays to measure $\mathrm{FT}_{4}$ of 23 pregnant women in the 3rd trimester, showed the very poor correlation among the different assays, with the majority of the patients having low $\mathrm{FT}_{4}$ levels when a nonpregnant reference range was used (20). Furthermore, $\mathrm{FT}_{4}$ measured by immunoassays has been shown to not have the expected inverse correlation with TSH in pregnancy (21). Finally, $\mathrm{FT}_{4}$ levels measured with immunoassays gradually fall as pregnancy progresses $(21,22)$.

In contrast to $\mathrm{FT}_{4}$, the $\mathrm{FT}_{4}$ index (typically calculated as total $\mathrm{T}_{4} \times$ thyroid hormone binding index) does have the expected small increase in the first trimester with subsequent decrease back to baseline and stabilization for the remainder of the pregnancy (22). It also exhibits the expected inverse relationship with TSH (22). However, this test is not widely available.

The direct methods of measuring $\mathrm{FT}_{4}$ such as equilibrium dialysis (ED) and ultrafiltration followed by LC/MS/MS are designed to be free from interference from changes in binding proteins and free from crossreactivity with heterophilic antibodies. These assays have shown better correlation with TSH than traditional immunoassays in nonpregnant patients (23), and show no correlation with albumin and TBG (24). However, there are important limitations in these methods as well. $\mathrm{FT}_{4}$ measured through ultrafiltration followed by tandem mass spectrometry in pregnancy does not have a good inverse correlation with TSH (21). Ultrafiltration can result in loss of $\mathrm{T}_{4}$ by adsorption to surfaces, while albumin separation depends on the membrane material used (25). ED takes a long time to perform (17-24h) and has the disadvantages of the effects of the in vitro dilution of possible serum protein-binding inhibitors as well as interference from buffer ingredients (25). Furthermore, both ED and ultrafiltration methods require expensive equipment, and their availability is very limited.

Total $\mathrm{T}_{4}\left(\mathrm{TT}_{4}\right)$ is an alternative method of assessment of thyroxine levels. As shown in multiple studies from around the world performed over the last few decades and summarized nicely by Lee et al. (22), $\mathrm{TT}_{4}$ levels consistently increase to $150 \%$ of the nonpregnant values. Therefore, one could use the $\mathrm{TT}_{4}$ measurement to assess thyroxine levels in pregnancy and multiply the nonpregnant reference range by 1.5 to get a pregnancyspecific reference range.

The 2011 American Thyroid Association guidelines recommend measuring $\mathrm{FT}_{4}$ in the dialysate or ultrafiltrate of serum samples using online extraction/liquid chromatography/tandem mass spectrometry (26). If that is not available, they recommend using 'whichever measure or estimate of $\mathrm{FT}_{4}$ is available', using method-specific and trimester-specific reference ranges (26). The 2012 Endocrine Society Guidelines regarding management of thyroid disease in pregnancy recommend using a trimester-specific range if measuring $\mathrm{FT}_{4}$, or measuring $\mathrm{TT}_{4}$ (with nonpregnant reference range multiplied by 1.5) or $\mathrm{FT}_{4} \mathrm{I}(27)$ in order to assess thyroxine levels in pregnancy. The 2014 European Thyroid Association guidelines recommend establishing trimester-specific reference ranges for $\mathrm{T}_{4}$ (total or free) (28). It is important for studies in this field to use one of these ways of assessing $\mathrm{T}_{4}$ when defining IMH. Existing studies examining adverse outcomes of $\mathrm{IMH}$ have all used $\mathrm{FT}_{4}$ assays to estimate thyroxine levels, as we review in a later section. One could therefore argue that the most informative assay clinically would be the $\mathrm{FT}_{4}$ immunoassay, assuming that trimesterspecific reference ranges are available.

\section{Definition and prevalence of IMH}

Unfortunately, consensus regarding the definition of IMH is lacking. In most studies, IMH is defined as an $\mathrm{FT}_{4}$ below the 2.5 th or 10 th percentile with a normal TSH. The 2011 American Thyroid Association's clinical guidelines on the management of thyroid disease in pregnancy defined IMH as a normal maternal TSH in conjunction with $\mathrm{FT}_{4}$ in the lower 5th or 10th percentile of the reference range (26). However, there are substantial differences in the definition of IMH between studies, which significantly affect the interpretation of prevalence data for this condition. Different studies use different $\mathrm{FT}_{4}$ percentile cutoffs, while there is no consistency in the assays used, and given the assay limitations described above, this creates disparate results. The reference ranges for $\mathrm{FT}_{4}$ and $\mathrm{TSH}$ are not defined in a uniform way, as they are not always established in an iodine-sufficient and anti-thyroid 
antibody negative pregnant population. The various studies use different gestational ages at the time of assessment, introducing added variability. Furthermore, ethnic variation as well as differential iodine status of the different populations further influences the $\mathrm{T}_{4}$ laboratory values.

With those caveats in mind, the prevalence of IMH in the literature has ranged from 1.3 to $23.9 \%$. Table 1 summarizes the prevalence data from different studies around the world, using different $\mathrm{FT}_{4}$ cutoffs for their definition (Table 1). It is clear that the prevalence of IMH is higher, as expected, in countries with more severe iodine deficiency $(36,37)$. In addition, the prevalence is higher in studies that do not use pregnancy-specific reference ranges, as these do not account for the observed decrease in $\mathrm{FT}_{4}$ seen with immunoassays in the pregnant state $(34,35)$.

\section{Causes of IMH}

The causes of IMH have not been completely delineated, but a number of new factors have been shown to be associated with this entity in recent years. The etiologies of IMH include iodine deficiency, environmental disruptors and novel causes such as obesity, iron deficiency and imbalance between pro- and antiangiogenic factors (Table 2).
The most common cause of IMH is iodine deficiency. As reviewed above, during pregnancy, thyroid hormone production needs to increase by approximately 50\%, while iodine clearance increases through higher glomerular filtration rate. When iodine becomes more scarce, the thyroid shifts its production of thyroid hormones from $T_{4}$ to $T_{3}$, to conserve iodine. Vermiglio et al. in Italy have shown that pregnant women consuming a moderately iodine-deficient diet have higher $\mathrm{T}_{3}$ and lower $\mathrm{T}_{4}$ levels than women with adequate iodine in their diet (38). Consequently, the prevalence of IMH is higher in countries with iodine deficiency (Table 1). Even though significant progress has been made in efforts to eradicate iodine deficiency worldwide, this is still an important issue, as 2014 data show that greater than $50 \%$ of European countries have mild iodine deficiency (39), while in the most recent NHANES data (2007-2010), 26\% of pregnant women in the US were found to have suboptimal iodine levels, with urinary iodine $<100 \mu \mathrm{g} / \mathrm{L}(40)$. The implications of these findings are important, as iodine deficiency affects not only maternal but also fetal thyroid hormone production. Iodine deficiency during gestation has been linked to lower IQ in the offspring $(41,42)$, with prompt iodine supplementation resulting in improvement in IQ (37, 43). It is critical to educate women seeking pregnancy to take a prenatal multivitamin with $150 \mu$ g iodine, to meet the goal of $250 \mu \mathrm{g}$ daily intake $(26,27)$.

Table 1 Prevalence of IMH.

\begin{tabular}{|c|c|c|c|}
\hline Study & $n$ & Country & $\begin{array}{c}\text { Lower } \mathbf{F T}_{\mathbf{4}} \text { cutoff } \\
\text { (percentile) }\end{array}$ \\
\hline (29) & 17298 & USA & $2.5 \%$ * \\
\hline (30) & 1099 & USA & $2.5 \% \#$ \\
\hline (31) & 1560 & UK & $2.5 \%$ * \\
\hline (32) & 4800 & China & $2.5 \%$ * \\
\hline
\end{tabular}

\begin{tabular}{c}
\hline $\begin{array}{c}\text { Normal TSH range } \\
(\mathrm{mU} / \mathrm{L}) \text { (how obtained) }\end{array}$ \\
\hline $0.08-2.99$ (PSRR) \\
$0.036-4.28$ (ND) \\
$0.213-3.93$ (ND) \\
$0.09-3.03$ (TSRR) \\
$0.59-4.38$ (GWSRR) \\
$0.21-3.8$ (GWSRR) \\
$0.09-2.96$ (GWSRR) \\
$0.5-3.29$ (GWSRR) \\
$0.35-3.88$ (GWSRR) \\
$0.29-5.22$ (TSRR) \\
$0.03-2.5$ (ES-G)
\end{tabular}

\begin{tabular}{|c|c|c|}
\hline $\begin{array}{c}\text { Gestational } \\
\text { week } \\
\end{array}$ & lodine status (at time of study) & Prevalence \\
\hline $6-20$ & Sufficient & $1.3 \%$ \\
\hline 1st trim & Sufficient & $2.1 \%$ \\
\hline 2nd trim & & $2.3 \%$ \\
\hline 1st trim & No data & $1.6 \%$ \\
\hline 4 & Sufficient & $2.1 \%$ \\
\hline \multicolumn{3}{|c|}{ - } \\
\hline \multicolumn{3}{|l|}{12} \\
\hline \multicolumn{3}{|l|}{16} \\
\hline \multicolumn{3}{|l|}{20} \\
\hline 4-8 & Sufficient & $2.4 \%$ \\
\hline \multirow[t]{2}{*}{$<18$ weeks } & Sufficient & $4.3 \%$ \\
\hline & & $8.5 \%$ \\
\hline$\leq 14$ weeks & Mildly deficient for pregnancy & $8.4 \%$ \\
\hline 1st trim & Deficient & $3.2 \%$ \\
\hline 2nd trim & & $12.7 \%$ \\
\hline 3rd trim & & $9.5 \%$ \\
\hline 1st trim & Deficient & $23.9 \%$ \\
\hline 2nd trim & & $20.6 \%$ \\
\hline 3rd trim & & $26.5 \%$ \\
\hline
\end{tabular}

ND, not disclosed; ES-G, Endocrine Society Guidelines; GWSRR, gestational week-specific reference range; PSRR, pregnancy-specific reference range; TSRR, trimester-specific reference range; $O R$, outside reference.

${ }^{*} \mathrm{FT}_{4}$ range adjusted for gestational age; ${ }^{*} \mathrm{FT}_{4}$ range not adjusted for gestational age; ${ }^{*}$ adjustment not reported. 
Thyroid autoimmunity, well recognized as a risk factor for the development of thyroid dysfunction during pregnancy due to failure of the autoimmune thyroid to meet the increased thyroxine demands, does not seem to be an important etiologic factor with respect to IMH. In a longitudinal study of 220 pregnant women in Italy, only $7 \%$ of women with IMH were found to have thyroid autoimmunity (anti-TPO Abs), similar to the rate in the general pregnant population (8\%) (36). In a larger study by Shan et al. of 4800 pregnant women in China, including 103 women with IMH, similar results were obtained, with $7-8 \%$ prevalence of thyroid autoimmunity in women with IMH, similar to nonpregnant controls (32).

Environmental contaminants are another factor that can cause selective $\mathrm{T}_{4}$ decrease in pregnancy. There are many pathways of $\mathrm{TH}$ metabolism and action that are influenced by environmental pollutants; these are summarized in a comprehensive review by Pearce and Braverman (44). A number of studies have specifically investigated these relationships in pregnant women. Organochlorine pesticides activate hepatic uridine diphosphate glucuronyl transferase, causing increased glucuronidation of $\mathrm{T}_{4}$ and subsequent drop in $\mathrm{T}_{4}$ levels. Their levels have been associated with low serum $\mathrm{T}_{4}$ in pregnancy $(45,46)$. Thiocyanate, a compound found in cigarette smoke, is a competitive sodium iodine symporter inhibitor, and $\mathrm{FT}_{4}$ index levels have been shown to be lower in smokers than nonsmokers (47). Finally, polychlorinated biphenyls antagonize $\mathrm{TH}$ binding at the level of the thyroid receptor. Exposure to these agents is inversely associated with low $\mathrm{T}_{4}$ levels in pregnancy (45).

Table 2 Causes of IMH.

\begin{tabular}{ll}
\hline Cause & Mechanism \\
$\begin{array}{c}\text { Environmental pollutants } \\
\text { Organochlorine pesticides }\end{array}$ & $\begin{array}{c}\text { Activation of hepatic } \\
\text { conserve iodine } \\
\text { glucuronidation }\end{array}$ \\
Thiocyanate & $\begin{array}{c}\text { Competitive inhibition } \\
\text { of sodium iodine symporter }\end{array}$ \\
Obolychlorinated biphenyls & $\begin{array}{c}\text { Binding to the nuclear } \\
\text { thyroid hormone receptor } \\
\text { ? Increased peripheral } \\
\text { deiodination }\end{array}$ \\
Iron deficiency? & $\begin{array}{c}\text { ? Reduced activity of the } \\
\text { heme-dependent thyroid } \\
\text { peroxidase }\end{array}$ \\
Angiogenic factors? & $\begin{array}{c}\text { Antiangiogenic effects on } \\
\text { thyroid }\end{array}$ \\
\hline
\end{tabular}

Obesity has also been recently associated with low $\mathrm{FT}_{4}$ levels, through mechanisms that are incompletely understood (33, 35, 48, 49, 50). Mannisto et al. first reported an inverse association of $\mathrm{FT}_{4}$ and body mass index (BMI) in iodine-sufficient anti-thyroid antibody negative pregnant women, while $\mathrm{FT}_{3}$ was directly related to BMI (48). Pop et al. first showed in 2013 that BMI at 12 weeks of gestation was inversely correlated with $\mathrm{FT}_{4}$ levels but not with TSH (49). Haddow et al. also showed that low $\mathrm{FT}_{4}$ is associated with higher BMI in pregnant women, both in a reference population and in women treated for hypothyroidism $(50,51)$. Han et al. in a longitudinal study of Chinese pregnant women (iodine sufficient) at 4-8 weeks of gestation confirmed the inverse association of $\mathrm{FT}_{4}$ with $\mathrm{BMI}$ in gestation and showed that the prevalence of IMH rises sharply when BMI increases above $24 \mathrm{~kg} / \mathrm{m}^{2}$ (33). One hypothesis regarding these findings, based on the increase in $T_{3}$ seen in association with the low $T_{4}$, is that in obesity, there is increased peripheral deiodination (52), as leptin, produced by adipose tissue, is known to stimulate $T_{4}$ to $T_{3}$ conversion $(53,54)$. The effect of obesity on maternal $\mathrm{T}_{4}$ levels is even more pronounced in iodine-deficient women, as shown in a recent study in Thailand, where mildly iodine-deficient overweight pregnant women had a 3.6-fold higher risk of developing low $\mathrm{FT}_{4}$ than women of normal weight (35).

Finally, recent studies have suggested that iron deficiency and fetal angiogenic factors may play a role in the regulation of $\mathrm{FT}_{4}$ levels. Iron deficiency is known to have multiple effects on the thyroid axis, and importantly affects $\mathrm{TH}$ synthesis by reducing the activity of the heme-dependent thyroid peroxidase (55). In the past, iron deficiency has been showed to be associated both with elevated $\mathrm{TSH}$ and with low $\mathrm{FT}_{4}$ levels in pregnancy (56). Hu et al. have shown that iron deficiency without anemia in pregnant rats can also cause inhibition of thyroid peroxidase and decrease in $\mathrm{TH}$ levels, with the effect being more pronounced for $\mathrm{T}_{4}$ than $\mathrm{T}_{3}$ (57). A recent cross-sectional study of 3340 pregnant women in China, with sufficient iodine intake and no evidence of thyroid autoimmunity, showed that iron deficiency in the first trimester was associated with IMH (OR of 2.440 for mild IMH, defined as $\mathrm{FT}_{4}<10 \%$, and $\mathrm{OR} 3.278$ for severe $\mathrm{IMH}$, defined as $\mathrm{FT}_{4}<5 \%$ ) (58). These risks were similar to those conferred by increased BMI. Finally, a recent study from the Netherlands showed that increasing levels of either proangiogenic placental growth factor (PlGF) or antiangiogenic soluble FMS-like tyrosine kinase-1 (sFlt1; a vascular endothelial growth factor (VEGF) and PlGF antagonist), both important pregnancy-specific 
angiogenesis regulators, are associated with increased risk of IMH (59). If these findings are replicated, future studies are needed to clarify the exact biological mechanisms behind these observed associations.

\section{Effects on the risk of pregnancy complications}

In the last two decades, a number of studies have investigated the effects of IMH on the risk of various pregnancy complications $(29,30,60,61,62,63,64,65$, $66,67,68,69,70)$. While most of these studies were underpowered due to their limited sample size, a few large studies have been performed. Casey et al. determined serum TSH and $\mathrm{FT}_{4}$ levels in 17298 women presenting for prenatal care in the first 20 weeks of pregnancy, and identified 233 women with $\mathrm{IMH}$, defined as a $\mathrm{FT}_{4}$ level below the pregnancy-specific 2.5th percentile (P2.5), with a normal-range TSH (P2.5-97.5) (60). Compared with women with normal-range $\mathrm{TSH}$ and $\mathrm{FT}_{4}$ levels, no differences in the risk of hypertensive disorders, diabetes, placental abruption and premature or cesarean deliveries were detected. In a similar approach, Cleary-Goldman et al. identified 232 and 247 women with IMH in the first and second trimesters of pregnancy, respectively, and studied their risk of a wide variety of pregnancy complications (30). While first-trimester IMH was associated with an increased risk of preterm labor and macrosomia, second-trimester IMH increased the risk of gestational diabetes, suggesting that the effects of IMH might be trimester-dependent. Although these endpoints are related and could therefore very well be the result of each other, the authors unfortunately did not perform conditional analyses. However, the results of this study need to be interpreted with caution, as a large number of tests were performed, which were not corrected for multiple testing. This is especially important, as for most of the tested associations, a clear a priori hypothesis based on pathophysiological mechanisms was lacking. In addition, many of the study endpoints were also rare, possibly leading to underpowered analyses. Interestingly, in a recent meta-analysis of Chan et al. including these and other smaller studies, the effects of IMH on the above-mentioned complications disappeared (68). Among the many endpoints studied, only the risk of placental abruption was found to be 2.3 times increased in mothers with IMH $(P=0.026)$. The conflicting results of these studies on the effects of IMH can be partly explained by various sources of heterogeneity between the individual studies. First of all, the definition of IMH was not consistent among studies, with $\mathrm{FT}_{4}$ lower-range cutoffs ranging from the 2 nd to a liberal 10th percentile (e.g., $(2,3,4,6))$, while there were also differences in the definitions of the normal ranges for $\mathrm{TSH}$ and $\mathrm{FT}_{4}$ levels (e.g., $(60,61,62))$. Furthermore, the timing of the diagnosis of IMH differed considerably, ranging from 10 to 13 weeks up until 20 weeks of pregnancy $(30,60,62)$. As discussed above, this might be important, as the study by Cleary-Goldman et al. suggested trimester-specific effects of IMH (30). In addition, there are large differences between studies with respect to the level of detail in which endpoints have been investigated. This is exemplified by a study in a large Dutch pregnancy cohort, in which the effects of thyroid dysfunction during early pregnancy on the risk of premature delivery were investigated, showing that IMH was associated with an increased risk of premature delivery (64). While most studies are not able to differentiate between spontaneous and iatrogenic deliveries, a subanalysis was performed on spontaneous premature deliveries only, showing that the association between IMH and prematurity was driven by spontaneous and not iatrogenic deliveries. This might partly explain why smaller studies without detailed information on spontaneous or iatrogenic deliveries have not been able to show any effects of IMH on the risk of prematurity. Lastly, as mentioned, there are substantial differences in sample sizes between studies, with many studies working with only a limited number of cases leading to underpowered analyses, while not applying multiple-testing correction for the many tests performed $(61,62,63,69)$.

Taken together, while some of the currently available studies suggest significant, albeit small, effects of IMH on the risk of pregnancy complications, large detailed and sufficiently powered studies using consistent definitions for IMH and adverse pregnancy outcomes are needed to clarify the exact effects of IMH on pregnancy complications.

\section{Effects on child neurodevelopment}

While there are only a limited number of large wellconducted studies on the effects of IMH on pregnancy complications, far more studies have been performed on the effects on child neurodevelopment. This is driven by the many studies showing that overt hypothyroidism during pregnancy negatively affects child neurodevelopment $(34,71,72,73,74,75,76,77,78,79,80,81,82,83,84,85$, $86)$. Table 3 provides an overview of the studies on IMH 


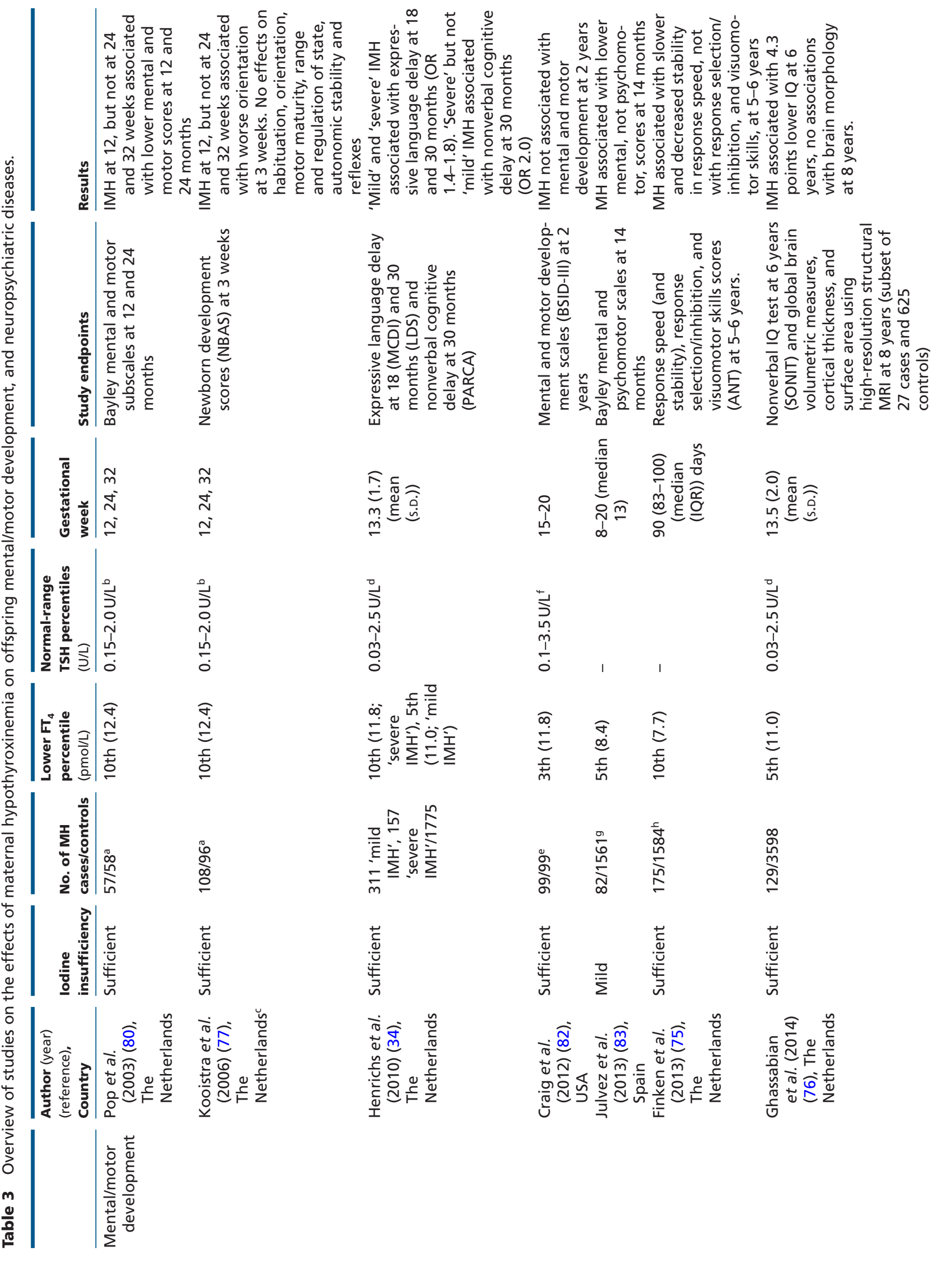



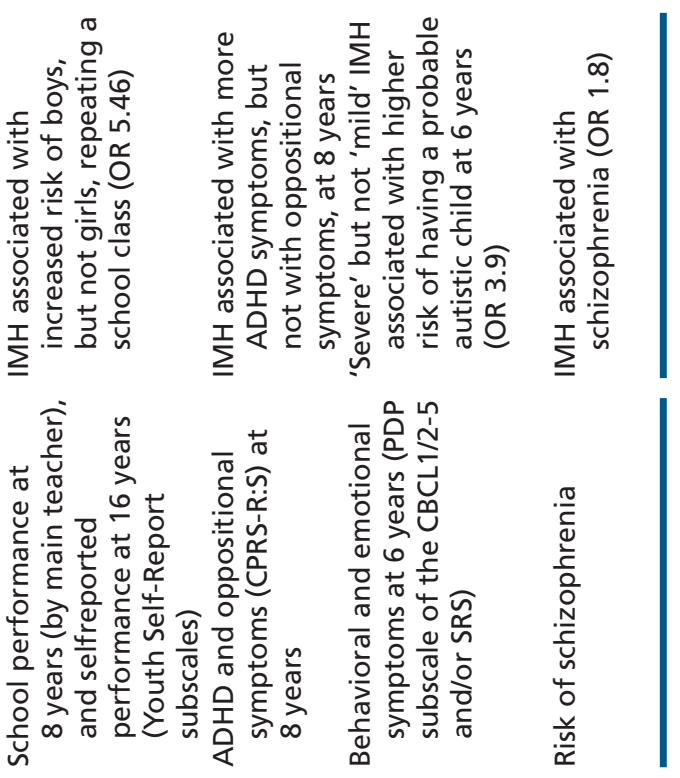

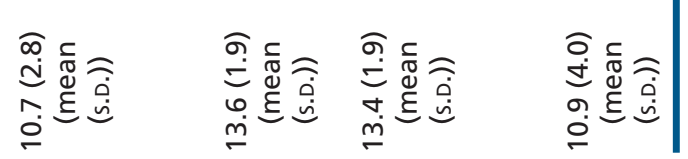

先

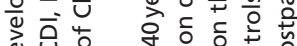

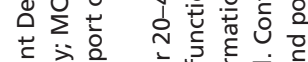

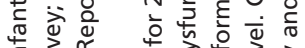
至主采

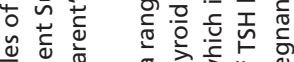

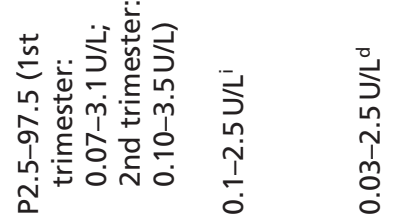

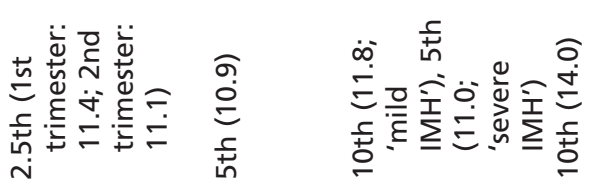

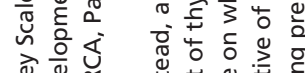

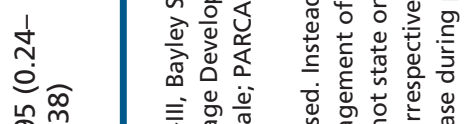

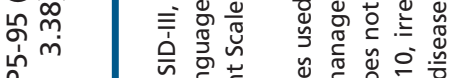

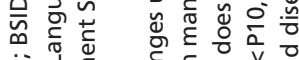

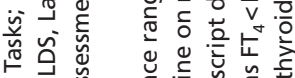

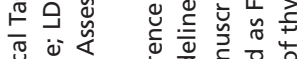

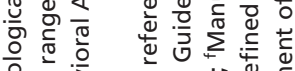
든 잉

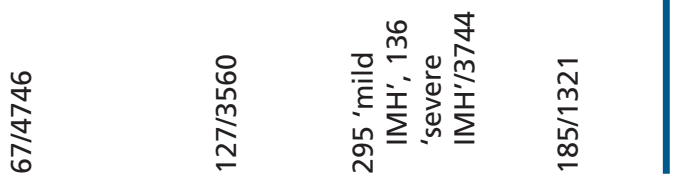

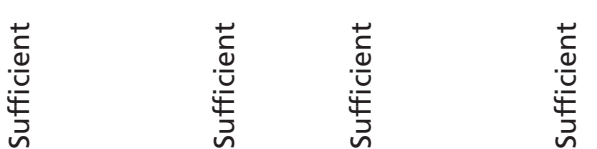

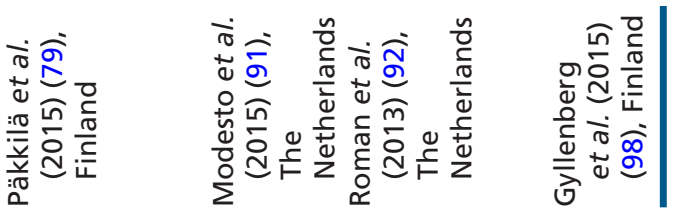
응 음

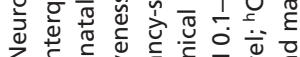

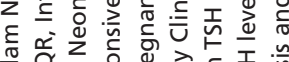

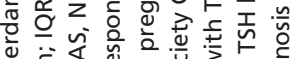

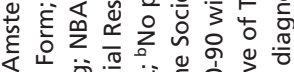

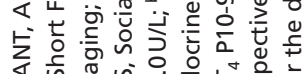

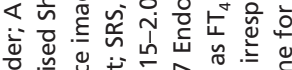

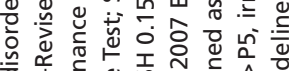

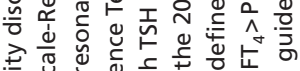

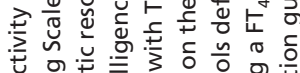

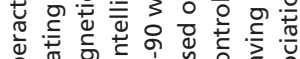
焉

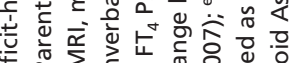

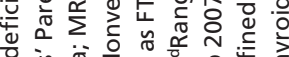

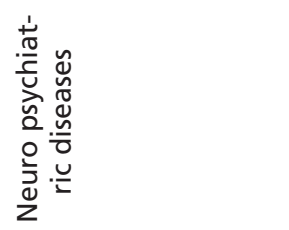

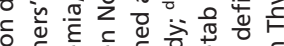

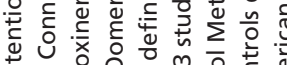

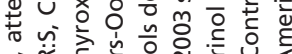

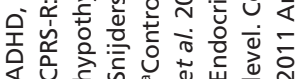


and child neurodevelopment, stratified by study endpoint (mental/motor development or psychiatric diseases). Only studies with an arbitrary cutoff of at least 50 IMH cases were included, to exclude underpowered studies with a high risk of spurious results.

\section{Mental development}

It has already been more than 50 years ago that Man et al. conducted the first prospective clinical study on the effects of IMH on child neurodevelopment $(71,72,73,74)$. Among 1349 pregnant women, 36 were identified with maternal hypothyroxinemia, of which 15 received adequate thyroid hormone $(\mathrm{TH})$ replacement therapy during pregnancy to correct the hypothyroxinemia. Children born to mothers with hypothyroxinemia and adequate $\mathrm{TH}$ replacement therapy had a similar development as children born to euthyroid mothers. However, children of inadequately treated mothers performed worse on various mental and motor scores at age 8 months, 4 and 7 years, including a lower mean IQ (at 7 years mean IQ 91.9 vs 104.5). Despite its small sample size, this study clearly illustrated the potential detrimental effects of low maternal thyroid function on the offspring. It surprisingly took the field more than 20 years before others started to study the effects of IMH on child neurodevelopment. In 2003, Pop et al. studied mental and motor development of 57 children born to mothers with IMH at 12 weeks gestation, defined as $\mathrm{FT}_{4}$ level below the pregnancy-specific P10 with a normal-range TSH level (80). Their development at both 1 and 2 years of age was compared with 58 children born from mothers with normal-range TSH and high-normal $\mathrm{FT}_{4}$ levels (P50-90). Children of mothers with IMH had worse mental and motor scores, with an average 8 and 10 points lower score on the Bayley mental and motor subscales. In an extension study of this cohort, including more cases and controls (Table 3), it was shown that in the children born from mothers with IMH, worse orientation scores could already be detected at 3 weeks of age (77). While very early neonatal behavior is rapidly evolving and difficult to assess, and the long-term predictive power of the used Neonatal Behavioral Assessment Scale remains questionable $(78,87)$, the results of the 2003 Pop et al. study showed that these children indeed continued to have worse neurodevelopmental scores at later timepoints. As cognition spans a broad range of subdomains, Henrichs et al. performed a study to gain more insight into the specific effects of IMH on cognitive functioning of the offspring (34). This study was performed in
3659 mother-child pairs from the Generation R study. Mild and severe IMH were defined as a pregnancy-specific $\mathrm{FT}_{4}$ level below P10 and P5 respectively with a normal TSH level. Mild and severe IMH were associated with a 1.3-1.8 times increased risk of expressive language delay at age 18 and 30 months, while severe IMH was also associated with a two-fold increased risk of nonverbal cognitive delay at age 30 months. More recently, Finken et al. showed that IMH in early pregnancy is associated with a reduced performance on a simple reaction time test and a decreased stability in response speed in 5-6-year-old offspring, while performance on visuomotor performance tests was normal (75). These results point to a slower information processing speed.

The majority of the previously reviewed studies focused on the effects of IMH on mental development in early life. As some of these cohorts have continued follow-up of their participants over the years, they have also been able to study cognitive performance in later life. Ghassabian et al. investigated the effects of early pregnancy IMH $(n=129)$, defined as a pregnancyspecific $\mathrm{FT}_{4}<\mathrm{P} 5$ with a normal-range TSH, on child IQ levels at 6 years of age (76). These children's IQ was on average 4.3 points lower than the IQ of children born from euthyroid mothers. This was also the first study to investigate the associations between IMH and magnetic resonance imaging (MRI)-derived brain morphological data at 8 years of age, which was performed in a subset of 27 cases and 625 controls. Despite the effects on IQ levels, no differences in brain morphology were detected. This can be either due to the small sample size or because of the structural alterations resulting from IMH, which may not be global but rather involve specific brain subregions. However, the absence of effects is most likely explained by the fact that nonlinear associations were not investigated, it has been shown that there is an inverted U-shaped relation between maternal $\mathrm{FT}_{4}$ and child IQ levels (84). This is supported by the fact that when data were reanalyzed using nonlinear models, associations of low $\mathrm{FT}_{4}$ with lower gray matter and cortex volumes were found (84). Finally, the effects of early pregnancy IMH on school performance of 8- and 16-year-old offspring have recently been investigated in the Northern Finland Birth Cohort 1986 (79). This study showed that boys, but not girls, from mothers with IMH during pregnancy had a 5.5 times increased risk of repeating a school class. Such an effect has not been examined in any of the previous studies on IMH. As these gender-specific effects could still be a chance finding, these results first need replication in an independent cohort. If the findings are replicated, 
the reasons behind the greater vulnerability of the male brains to IMH will need further investigation.

While the above studies clearly show that IMH is associated with worse cognitive performance, the study by Craig et al. did not find any effects of IMH on mental and motor scales at 2 years of age (Table 3) (82). This can be explained by the fact that this study investigated the effects of IMH diagnosed in gestational week 15-20, whereas the essential role of $\mathrm{TH}$ in brain development is predominantly restricted to the first trimester of pregnancy (4).

\section{Motor development}

Since overt maternal hypothyroidism increases the risk of not only mental but also motor neurodevelopmental delay (32), studies have also investigated whether IMH affects the motor development of the child (Table 3) $(75,77,80,82,83)$. Indeed, most of these studies showed that IMH during early pregnancy is associated with an increased risk of a delay in motor development. The largest study was performed by Costeira et al. in a moderately iodine-deficient area in Portugal (81). Children born from mothers with an $\mathrm{FT}_{4}$ below P25 had a 2.1-fold increased risk of mild-to-severe delay in psychomotor development. While these results are obviously not generalizable to iodine-sufficient areas, it is important to note that other studies from iodine-sufficient regions have also shown an increased risk of a delay in motor development in children born from mothers with $\operatorname{IMH}(80,85,86)$. As shown in Table 3, two studies did not find an effect of IMH on motor development of the child $(82,83)$. This can be partly explained by the fact that, in the study by Julvez et al., the control group included all mothers with an $\mathrm{FT}_{4}$ above the hypothyroxinemia $\mathrm{FT}_{4}$ cutoff (83). This group therefore also included mothers with high $\mathrm{FT}_{4}$ levels, and it has been shown that not only low but also high and even high-normal $\mathrm{FT}_{4}$ levels can negatively affect child neurodevelopment (84). Furthermore, the authors tested the effects of low $\mathrm{FT}_{4}$ levels, irrespective of the TSH status, and therefore tested a heterogeneous group that contained both purely hypothyroxinemic and overtly hypothyroid subjects. The negative findings in the study by Craig et al. (82) could be due to the fact that the effects of only second-trimester IMH were tested, beyond the timeframe when TH plays a crucial role in neurodevelopment (4). Taken together, these studies strongly suggest that IMH is associated with a delay not only in mental development but also in motor development, while more work is needed to clarify the exact effects on the various subdomains of motor development, such as gross and fine motor skills, muscle control, body coordination and locomotion.

\section{Neuropsychiatric diseases}

In recent years, interest has shifted toward studying the effects of IMH on neuropsychiatric diseases. In 1993, Hauser et al. had already shown that individuals with a mutation in the $\mathrm{TH}$ receptor beta gene have an increased risk of attention-deficit hyperactivity disorder (ADHD) (89). A few years later, it was also shown that transgenic mice harboring a mutation in this receptor display ADHD-like symptoms, including hyperactivity and learning deficits (90). Recently, Modesto et al. studied the association between IMH and ADHD symptoms at age 8 years in 3873 mother-child pairs from the Generation R Study (91). Children born from mothers with IMH, defined as an $\mathrm{FT}_{4}$ below the pregnancy-specific P5 with a normal-range TSH, had more ADHD symptoms, compared with children born from euthyroid mothers. These effects persisted after controlling for multiple confounders, including children's IQ. These motherchild pairs were also the subject of another study on autism (92), as transient gestational hypothyroxinemia in rodents has been shown to induce cortical neuronal migration brain lesions resembling those of autism $(13,14,93,94)$. When the children were 6 years of age, their parents completed questionnaires on behavioral and emotional symptoms. Children born from mothers with IMH showed more autistic symptoms compared with children from euthyroid mothers. Importantly, these effects were independent from the effects on ADHD symptoms. Besides, in these mother-child pairs, it has also been shown that IMH is associated with a larger fetal and infant head size (95), while it is known that children with autism spectrum disorders show increased head growth (96). Unfortunately, the authors did not correct the analyses on autism for head size, which could provide more insight into how these endpoints are related to one another.

Finally, schizophrenia is associated with disrupted prenatal neurodevelopment and impaired cognitive function (97), which is similar to the consequences of IMH. Gyllenberg et al. has studied the prevalence of $\mathrm{IMH}$, defined as a pregnancy-specific $\mathrm{FT}_{4}$ below $\mathrm{P} 10$ with a normal-range TSH, in 1010 case-control pairs from the Finnish Prenatal Study of Schizophrenia (98). IMH was associated with 1.8 times increased risk of schizophrenia, even after adjusting for confounders including maternal psychiatric history. 
Taken together, while the number of studies on the effects of IMH on neuropsychiatric endpoints are still limited and therefore need replication in independent cohorts, the currently available data strongly suggest that IMH should be seen as a risk factor not only for impaired mental and motor neurodevelopment but also for neuropsychiatric diseases of the offspring.

\section{Prevention and treatment of maternal hypothyroxinemia}

As the above studies have clearly shown an association between IMH in early pregnancy and child neurodevelopment, the key clinical question remaining is whether these complications can be prevented by timely correction of IMH. In the previously discussed studies by Man et al., it was shown that the 15 children born to mothers with adequately treated IMH had a normal development, while the 21 children born to mothers with inadequately treated IMH had a worse mental and motor development $(71,72,73,74)$. However, this study is obviously limited by its small sample size, while the hypothyroxinemic group included mothers with not only IMH but also overt hypothyroidism. In the previously discussed Pop et al. study, a subgroup of 15 children, born from mothers with IMH at 12 weeks gestation but in whom $\mathrm{FT}_{4}$ had increased at 24 and 32 weeks' gestation, had a similar development as the controls. While this observation is also based on only a limited number of subjects, and it is unclear when $\mathrm{FT}_{4}$ started to normalize between 12 and 24 weeks gestation, these findings raise the question of whether, similar to the animal data described previously, correction of IMH in early pregnancy could potentially reverse the detrimental neurodevelopmental effects on the offspring. Two randomized controlled trials (RCTs) have studied the effects of levothyroxine treatment of women with IMH and (subclinical) hypothyroidism on child IQ. The Controlled Antenatal Thyroid Screening (CATS) study (99) randomized 21846 women recruited in early pregnancy to testing of TSH and $\mathrm{FT}_{4}$ levels during pregnancy versus serum sample storage and measurement after pregnancy. Women in the screening group with a $\mathrm{TSH}>\mathrm{P} 97.5$, an $\mathrm{FT}_{4}<\mathrm{P} 2.5$, or both, were treated with a starting dose of $150 \mu \mathrm{g}$ levothyroxine, with dose adjustments on subsequent thyroid function testing. An intention-to-treat analysis showed no difference in the children's IQ at 3 years, including mean IQ levels and percentage of children with $\mathrm{IQ}<85$ points, between the treated and nontreated group. A subanalysis restricted to the mothers with IMH ( $\mathrm{FT}_{4}$ levels $\left.<\mathrm{P} 2.5(N=411)\right)$ also did not show any significant differences. However, this study has a number of potential limitations. First, the study was not powered for the subgroup of mothers with IMH only. Second, one can question if an IQ test at 3 years is a reliable test for the detrimental effects of a shortage of $\mathrm{TH}$ on the fetal brain. For example, children born with congenital hypothyroidism who are treated promptly do not have a lower IQ, while they may have more subtle deficiencies in integrative and sensory functions (100). Third, the CATS study did not compare the IQ levels of the children born from mothers with thyroid dysfunction to children born from euthyroid mothers, and it therefore remains unclear if their screening strategy was effective at all in identifying a high-risk group. Finally, while brain development mainly takes place in the first trimester, treatment was started at a median gestational age of 13 weeks and 3 days. This may have been too late to restore any detrimental effects of $\mathrm{TH}$ shortage. The timing of levothyroxine intervention is a critical point, as animal models of IMH reviewed earlier, such as by Auso et al., have shown that the neurodevelopmental effects on offspring born to hypothyroxinemic dams could only be rescued by $\mathrm{TH}$ replacement therapy in early pregnancy, but not with later intervention (13). Recently, also the first results of the Thyroid Therapy for Mild Thyroid Deficiency in Pregnancy study ('TSH study') were presented at the Society for Maternal-Fetal Medicine's Annual Meeting (101). For this RCT on the treatment of subclinical hypothyroidism and IMH, 97226 pregnant women underwent $\mathrm{TSH}$ and $\mathrm{FT}_{4}$ testing. Women with $\mathrm{IMH}$ $(n=526)$, defined as an $\mathrm{FT}_{4}<0.86 \mathrm{ng} / \mathrm{dL}(11.1 \mathrm{pmol} / \mathrm{L})$ with a normal-range TSH (0.08-3.99 U/L), were randomized to either levothyroxine or placebo at a mean gestational age of 17 weeks. Preliminary results showed no significant difference in offspring IQ at 5 years of age between the treated and untreated groups. Unfortunately, this study also has various limitations in common with the CATS study, including the fact that treatment was started at an even later timepoint in gestation. Furthermore, this study was designed to be powered to detect a 5-point difference in IQ at 5 years of age, while the study by Ghassabian et al. showed that IMH only leads to a 4.3 points lower IQ at 6 years of age (76). This suggests that this study would be underpowered to detect an effect of treatment of IMH with levothyroxine, even if this treatment would lead to a full restoration of a 4.3 point IQ loss. Over the years, various international guidelines on the treatment of thyroid dysfunction during pregnancy have provided recommendations on the treatment of $\operatorname{IMH}(26,27,28)$. 
While the ATA guidelines published in 2011 recommended to not treat IMH, as solid evidence for a treatment benefit of IMH was still lacking (26), the 2011 Endocrine Society guidelines already left the choice of treatment to the discretion of the caregiver (27). The 2014 ETA guidelines also recommended to consider treatment of $\mathrm{IMH}$, but importantly note that this should only be considered in the first trimester of pregnancy, when most harms of IMH on brain development are expected to take place (28). When considering treatment of IMH, one should also take the potential consequences of overtreatment into account, which inevitably takes place in a subset of treated patients. In this context, it is interesting to note that Korevaar et al. recently investigated the associations between early pregnancy thyroid function, child IQ at 6 years and brain MRI scans at 8 years of age (84). This study showed that not only low-normal early pregnancy $\mathrm{FT}_{4}$ levels but also high-normal $\mathrm{FT}_{4}$ levels are associated with decreased IQ levels of the offspring, as well as with smaller gray matter and cortex volumes. Although this study did not include mothers on $\mathrm{TH}$ replacement therapy, this study does suggest that treatment of IMH might carry the risk of adverse child neurodevelopment when the goal of treatment is to achieve high-normal $\mathrm{FT}_{4}$ results. Given the above considerations, it is clear that a sufficiently powered RCT on the treatment of IMH early in the first trimester of pregnancy is still needed in order to answer the question of whether IMH should be treated or not.

\section{A role for iodine supplementation}

As discussed previously, iodine deficiency is still a global problem, affecting a subset of many European and United States' population. Restoring iodine status would be a relatively easy way to treat IMH in iodine-deficient women. In 2009, Berbel et al. studied the effects of iodine supplementation in early pregnancy in women with IMH from an iodine-deficient area in Spain (37). This study consisted of three groups: Group 1, children born from euthyroid mothers that started iodine supplementation at 4-6 weeks of gestation; Group 2, children born from mothers with early pregnancy IMH who started iodine supplementation at gestational weeks 10-12; and Group 3, children born from mothers with IMH at gestational weeks $37-40$ who were treated with iodine supplementation after delivery and during lactation. Of the children born from mothers in group 2 and 3, 25.0 and $36.8 \%$ had neurodevelopmental delay at 18 months, while none of the children born from mothers in group
1 had neurodevelopmental delay. These results highlight the importance of optimizing iodine status in pregnant women as early in pregnancy as possible, preferably before conception, as has also been shown by others $(37,43)$. Optimizing iodine status of pregnant women asks for concerted actions by national authorities (102). On the individual level, the treating physician should, especially when dealing with pregnant women with IMH, get a sense of the iodine status of the patient by asking her dietary habits and intake of iodine-containing multivitamins. If needed, iodine supplementation should be started early, ideally a few months before conception, ensuring a daily intake of $250 \mu \mathrm{g} /$ day $(26,27,28,102)$. Recently, Moleti et al. investigated the effects of iodine supplementation on child IQ in a prospective observational study in 60 mother-child pairs from an iodine-deficient region in Italy (103). Stratified for maternal histories of iodized salt consumption and levothyroxine treatment before and during pregnancy, the IQ test scores of the children at 6-12 years of age were compared. Irrespective of levothyroxine treatment, women consuming iodized salt for at least 2 years before pregnancy had children with better IQ scores compared with women not using iodine supplementation. Based on this, the authors suggested that neurodevelopmental outcome of children might be more dependent on maternal iodine status than on maternal thyroid function. Of note, this study was based on a limited sample size, with only 15 pairs per group, while many statistical tests were performed, resulting in a high risk of false-positive findings. Therefore, these results need to be interpreted with caution and first need replication in an independent, sufficiently powered study, ideally in a randomized controlled trial.

Finally, future studies should clarify whether also the iron status of these women should be determined, as one Chinese study showed that iron deficiency is associated with 2.4 times increased risk of IMH (58). Importantly, these effects were independent of iodine deficiency, and are supported by various studies showing that iron deficiency impairs TH synthesis and metabolism $(55,104,105)$. However, as no other studies have investigated this association in pregnant women, replication in an independent study is warranted.

\section{Remaining uncertainties}

Although significant progress has been made in the last decade in the understanding of the detrimental effects of IMH during pregnancy, many uncertainties still surround this common disease, including its causes, 
effects and treatment (Table 4). Currently, only iodine deficiency and several environmental pollutants are well-established causes of IMH. While obesity, abnormal levels of angiogenic factors and iron deficiency have all been associated with $\mathrm{IMH}$, insight into the underlying pathogenetic mechanisms is still lacking. The fact that IMH is not associated with one but various risk factors could suggest that IMH is a heterogeneous group of diseases. A better understanding of its risk factors and underlying mechanisms is therefore not merely of academic interest; it is also essential to provide a basis for tailored management of IMH. Furthermore, the long-term effects of IMH have not been investigated, with existing studies focusing on the development of children in their first few years of life (Table 3). It is known that TH deficiency during critical early stages of neurodevelopment results in structural and functional changes in the brain $(4,13,17)$, which are expected to cause irreversible neurological outcomes, with their severity depending on the degree of TH deficiency. IMH is therefore expected to have some impact on 'hard endpoints' later in life, such as academic achievement, socioeconomic status, quality of life and mortality. However, these effects still need to be characterized. Future studies on these endpoints should apply a consistent definition of IMH, using pregnancy- and population-specific reference ranges, while the exact $\mathrm{FT}_{4}$ cutoff percentile for IMH still remains debatable, as studies have used a wide range of cutoff levels, with varying results (Table 3 ). Sensitivity analyses to pinpoint at what exact $\mathrm{FT}_{4}$ level the detrimental effects start to occur will be informative. These studies should focus not only on child developmental outcomes, but also on the risk of pregnancy complications, as the currently available data on the latter risks remain inconclusive. Importantly, these studies should be carried out in well-documented cohorts with available

Table 4 Isolated maternal hypothyroxinemia: the knowns and unknowns.

Knowns
Common disease
Risk factors include iodine deficiency, environmental
pollutants and obesity
Negatively affects child mental and motor development
Unknowns
Other risk factors and underlying pathophysiological
mechanisms
Effects on pregnancy complications
Effects on mental and motor function in later life
Effects of treatment early in the first trimester

information on important potential confounders, such as socioeconomic status and parental educational levels.

While these studies will be important for developing a more precise definition of IMH and understanding of its clinical complications, the key clinical question, which still needs to be answered, is whether these complications can be prevented by timely correction of IMH. Ensuring a sufficient iodine status is essential, but it remains unclear if correction of IMH with TH replacement therapy is beneficial. As discussed, the two RCTs on treatment of maternal thyroid hypofunction in pregnancy were underpowered for IMH, while treatment started in the late first or early second trimester, when an important part of brain development has already taken place. It could therefore very well be that these studies missed the 'window of opportunity' of a successful intervention in the early first trimester, leading to negative results. We therefore call for a sufficiently powered, placebocontrolled RCT on the treatment of IMH with TH in the early first trimester. While there are insufficient data to recommend a specific gestational week when treatment should be started, it seems reasonable to aim for a treatment as early in the first trimester as possible, preferably before the sixth week of pregnancy $(6,7)$. If proven successful, treating pregnant women with IMH in early first trimester will be challenging, as most women do not present to antenatal care facilities before the second half of the first trimester. This will require concerted actions by national health authorities to increase public awareness of this condition and the need to present to antenatal care facilities as soon as pregnancy is confirmed. The road toward developing the optimal management of IMH is still challenging, but important to pursue given the condition's prevalence and potential complications.

Declaration of interest

The authors declare that there is no conflict of interest that could be perceived as prejudicing the impartiality of the research reported.

\section{Funding}

This research did not receive any specific grant from any funding agency in the public, commercial or not-for-profit sector.

\section{References}

1 Burrow GN, Fisher DA \& Larsen PR. Maternal and fetal thyroid function. New England Journal of Medicine 1994331 1072-1078. (doi:10.1056/NEJM199410203311608)

2 Glinoer D. The regulation of thyroid function in pregnancy: pathways of endocrine adaptation from physiology to pathology. Endocrine Reviews 199718 404-433. (doi:10.1210/edrv.18.3.0300) 
3 Glinoer D. Pregnancy and iodine. Thyroid 200111 471-481. (doi:10.1089/105072501300176426)

4 Williams GR. Neurodevelopmental and neurophysiological actions of thyroid hormone. Journal of Neuroendocrinology 200820 784-794. (doi:10.1111/j.1365-2826.2008.01733.x)

5 Morreale de Escobar G, Obregon MJ \& Escobar del Rey F. Role of thyroid hormone during early brain development. European Journal of Endocrinology 2004151 (Supplement 3) U25-U37. (doi:10.1530/ eje.0.151U025)

6 Bernal J \& Pekonen F. Ontogenesis of the nuclear 3,5,3'-triiodothyronine receptor in the human fetal brain. Endocrinology 1984114 677-679. (doi:10.1038/363458a0)

7 Contempré B, Jauniaux E, Calvo R, Jurkovic D, Campbell S \& de Escobar GM. Detection of thyroid hormones in human embryonic cavities during the first trimester of pregnancy. Journal of Clinical Endocrinology and Metabolism 199377 1719-1722. (doi:10.1210/jc.77.6.1719)

8 Ferreiro B, Bernal J, Goodyer CG \& Branchard CL. Estimation of nuclear thyroid hormone receptor saturation in human fetal brain and lung during early gestation. Journal of Clinical Endocrinology and Metabolism 198867 853-856. (doi:10.1210/jcem-67-4-853)

9 Iskaros J, Pickard M, Evans I, Sinha A, Hardiman P \& Ekins R. Thyroid hormone receptor gene expression in first trimester human fetal brain. Journal of Clinical Endocrinology and Metabolism 200085 2620-2623. (doi:10.1210/jcem.85.7.6766)

10 Kester MH, Martinez de Mena R, Obregon MJ, Marinkovic D, Howatson A, Visser TJ, Hume R \& Morreale de Escobar G. Iodothyronine levels in the human developing brain: major regulatory roles of iodothyronine deiodinases in different areas. Journal of Clinical Endocrinology and Metabolism 200489 3117-3128. (doi:10.1210/jc.2003-031832)

11 Chatonnet F, Flamant F \& Morte B. A temporary compendium of thyroid hormone target genes in brain. Biochimica et Biophysica Acta 20151849 122-129. (doi:10.1016/j.bbagrm.2014.05.023)

12 Berbel P, Navarro D \& Román GC. An evo-devo approach to thyroid hormones in cerebral and cerebellar cortical development: etiological implications for autism. Frontiers in Endocrinology 20145 1-28. (doi:10.3389/fendo.2014.00146)

13 Ausó E, Lavado-Autric R, Cuevas E, Del Rey FE, Morreale De Escobar G \& Berbel P.A moderate and transient deficiency of maternal thyroid function at the beginning of fetal neocorticogenesis alters neuronal migration. Endocrinology 2004 145 4037-4047. (doi:10.1210/en.2004-0274)

14 Lavado-Autric R, Ausó E, García-Velasco JV, Arufe Mdel C, Escobar del Rey F, Berbel P \& Morreale de Escobar G.Early maternal hypothyroxinemia alters histogenesis and cerebral cortex cytoarchitecture of the progeny. Journal of Clinical Investigation 2003 111 1073-1082. (doi:10.1172/JCI200316262)

15 Wang Y, Wang Y, Dong J, Wei W, Song B, Min H, Teng W \& Chen J. Developmental hypothyroxinaemia and hypothyroidism limit dendritic growth of cerebellar Purkinje cells in rat offspring: involvement of microtubule-associated protein 2 (MAP2) and stathmin. Neuropathology and Applied Neurobiology 201440 398-415. (doi:10.1111/nan.12074)

16 Wei W, Wang Y, Wang Y, Dong J, Min H, Song B, Teng W, Xi Q \& Chen J. Developmental hypothyroxinaemia induced by maternal mild iodine deficiency delays hippocampal axonal growth in the rat offspring. Journal of Neuroendocrinology 201325 852-862. (doi:10.1111/jne.12058)

17 Opazo MC, Gianini A, Pancetti F, Azkcona G, Alarcón L, Lizana R, Noches V, Gonzalez PA, Porto M, Mora S et al. Maternal hypothyroxinemia impairs spatial learning and synaptic nature and function in the offspring. Endocrinology 2008149 5097-5106. (doi:10.1210/en.2008-0560)

18 Oppenheimer JH. Role of plasma proteins in the binding, distribution, and metabolism of the thyroid hormones. New
England Journal of Medicine 1968278 1153-1162. (doi:10.1056/ NEJM196805232782107)

19 Hoffenberg R \& Ramsden DB. The transport of thyroid hormones. Clinical Science 198365 337-342. (doi:10.1042/cs0650337)

20 Sapin R, D'Herbomez M \& Schlienger JL. Free thyroxine measured with equilibrium dialysis and nine immunoassays decreases in late pregnancy. Clinical Endocrinology 200450 581-584.

21 Kahric-Janicic N, Soldin SJ, Soldin OP, West T, Gu J \& Jonklaas J. Tandem mass spectrometry improves the accuracy of free thyroxine measurements during pregnancy. Thyroid 200717 303-311. (doi:10.1089/thy.2006.0303)

22 Lee RH, Spencer CA, Mestman JH, Miller EA, Petrovic I, Braverman LE \& Goodwin TM. Free T4 immunoassays are flawed during pregnancy. American Journal of Obstetrics and Gynecology 2009 200 260.e1-260.e6. (doi:10.1016/j.ajog.2008.10.042)

23 Jonklaas J, Kahric-Janicic N, Soldin OP \& Soldin SJ. Correlations of free thyroid hormones measured by tandem mass spectrometry and immunoassay with thyroid-stimulating hormone across 4 patient populations. Clinical Chemistry 200955 1380-1388. (doi:10.1373/ clinchem.2008.118752)

24 van Deventer HE, Mendu DR, Remaley AT \& Soldin SJ. Inverse log-linear relationship between thyroid-stimulating hormone and free thyroxine measured by direct analog immunoassay and tandem mass spectrometry. Clinical Chemistry 201157 122-127. (doi:10.1373/clinchem.2010.154088)

25 Holm SS, Hansen SH, Faber J \& Staun-Olsen P. Reference methods for the measurement of free thyroid hormones in blood. Evaluation of potential reference methods for free thyroxine. Clinical Biochemistry 200437 85-93. (doi:10.1016/j. clinbiochem.2003.09.009)

26 Stagnaro-Green A, Abalovich M, Alexander E, Azizi F, Mestman J, Negro R, Nixon A, Pearce EN, Soldin OP, Sullivan S et al. American Thyroid Association Taskforce on Thyroid Disease During Pregnancy and Postpartum. Guidelines of the American Thyroid Association for the diagnosis and management of thyroid disease during pregnancy and postpartum. Thyroid 201121 1081-1125. (doi:10.1089/ thy.2011.0087)

27 De Groot L, Abalovich M, Alexander EK, Amino N, Barbour L, Cobin RH, Eastman CJ, Lazarus JH, Luton D, Mandel SJ et al. Management of thyroid dysfunction during pregnancy and postpartum: an Endocrine Society clinical practice guideline. Journal of Clinical Endocrinology and Metabolism 201297 2543-2565. (doi:10.1210/jc.2011-2803)

28 Lazarus J, Brown RS, Daumerie C, Hubalewska-Dydejczyk A, Negro R \& Vaidya B. European thyroid association guidelines for the management of subclinical hypothyroidism in pregnancy and in children. European Thyroid Journal 20143 76-94. (doi:10.1159/000362597)

29 Casey BM, Dashe JS, Spong CY, McIntire DD, Leveno KJ \& Cunningham GF. Perinatal significance of isolated maternal hypothyroxinemia identified in the first half of pregnancy. Obstetrics \& Gynecology 2007109 1129-1135. (doi:10.1097/01. aog.0000262054.03531.24)

30 Cleary-Goldman J, Malone FD, Lambert-Messerlian G, Sullivan L, Canick J \& Porter TF. Maternal thyroid hypofunction and pregnancy outcome. Obstetrics \& Gynecology 2008112 85-92.

31 Vaidya B, Anthony S, Bilous M, Shields B, Drury J, Hutchison S $\&$ Bilous R. Detection of thyroid dysfunction in early pregnancy: universal screening or targeted high-risk case finding? Journal of Clinical Endocrinology and Metabolism 200792 203-207. (doi:10.1210/jc.2006-1748)

32 Shan ZY, Chen YY, Teng WP, Yu XH, Li CY, Zhou WW, Gao B, Zhou JR, Ding B, Ma Y et al. A study for maternal thyroid hormone deficiency during the first half of pregnancy in China. European Journal of Clinical Investigation 200939 37-42. (doi:10.1111/j.13652362.2008.02055.x) 
33 Han C, Li C, Mao J, Wang W, Xie X, Zhou W, Li C, Xu B, Bi L, Meng $\mathrm{T}$ et al. High body mass index is an indicator of maternal hypothyroidism, hypothyroxinemia, and thyroid-peroxidase antibody positivity during early pregnancy. BioMed Research International 20152015 351831. (doi:10.1155/2015/351831)

34 Henrichs J, Bongers-Schokking JJ, Schenk JJ, Ghassabian A, Schmidt HG, Visser TJ, Hooijkaas H, de Muinck Keizer-Schrama SM, Hofman A, Jaddoe VV et al. Maternal thyroid function during early pregnancy and cognitive functioning in early childhood: the generation R study. Journal of Clinical Endocrinology and Metabolism 201095 4227-4234. (doi:10.1210/jc.2010-0415)

35 Gowachirapant S, Melse-Boonstra A, Winichagoon P \& Zimmermann MB. Overweight increases risk of first trimester hypothyroxinaemia in iodine-deficient pregnant women. Maternal and Child Nutrition 201410 61-71. (doi:10.1111/mcn.12040)

36 Moleti M, Lo Presti VP, Mattina F, Mancuso A, De Vivo A, Giorgianni G, Di Bella B, Trimarchi F \& Vermiglio F. Gestational thyroid function abnormalities in conditions of mild iodine deficiency: early screening versus continuous monitoring of maternal thyroid status. European Journal of Endocrinology 2009160 611-617. (doi:10.1530/EJE-08-0709)

37 Berbel P, Mestre JL, Santamaría A, Palazón I, Franco A, Graells M, González-Torga A \& de Escobar GM. Delayed neurobehavioral development in children born to pregnant women with mild hypothyroxinemia during the first month of gestation: the importance of early iodine supplementation. Thyroid 200919 511-519. (doi:10.1089/thy.2008.0341)

38 Vermiglio F, Lo Presti VP, Scaffidi Argentina G, Finocchiaro MD, Gullo D, Squatrito S \& Trimarchi F. Maternal hypothyroxinaemia during the first half of gestation in an iodine deficient area with endemic cretinism and related disorders. Clinical Endocrinology 1995 42 409-415. (doi:10.1111/j.1365-2265.1995.tb02650.x)

39 Zimmermann MB, Gizak M, Abbott K, Andersson M \& Lazarus JH. Iodine deficiency in pregnant women in Europe. Lancet Diabetes \& Endocrinology 20153 672-674. (doi:10.1016/s2213-8587(15)00263-6)

40 Caldwell KL, Pan Y, Mortensen ME, Makhmudov A, Merrill L \& Moye J. Iodine status in pregnant women in the National Children's Study and in U.S. women (15-44 years), National Health and Nutrition Examination Survey 2005-2010. Thyroid 201323 927-937. (doi:10.1089/thy.2013.0012)

41 Bath SC, Steer CD, Golding J, Emmett P \& Rayman MP. Effect of inadequate iodine status in UK pregnant women on cognitive outcomes in their children: results from the Avon Longitudinal Study of Parents and Children (ALSPAC). Lancet 2013382 331-337. (doi:10.1016/S0140-6736(13)60436-5)

42 Hynes KL, Otahal P, Hay I \& Burgess JR. Mild iodine deficiency during pregnancy is associated with reduced educational outcomes in the offspring: 9-year follow-up of the gestational iodine cohort. Journal of Clinical Endocrinology and Metabolism 201398 1954-1962. (doi:10.1210/jc.2012-4249)

43 Velasco I, Carreira M, Santiago P, Muela JA, Garcia-Fuentes E, Sanchez-Munoz B, Garriga MJ, Gonzalez-Fernandez MC, Rodriguez A, Caballero FF et al. Effect of iodine prophylaxis during pregnancy on neurocognitive development of children during the first two years of life. Journal of Clinical Endocrinology and Metabolism 200994 3234-3241. (doi:10.1210/jc.2008-2652)

44 Pearce EN \& Braverman LE. Environmental pollutants and the thyroid. Best Practice \& Research. Clinical Endocrinology \& Metabolism 200923 801-813. (doi:10.1016/j.beem.2009.06.003)

45 Chevrier J, Eskenazi B, Holland N, Bradman A \& Barr DB. Effects of exposure to polychlorinated biphenyls and organochlorine pesticides on thyroid function during pregnancy. American Journal of Epidemiology 2008168 298-310. (doi:10.1016/j.jri.2012.10.006)

46 Lopez-Espinosa MJ, Vizcaino E, Murcia M, Llop S, Espada M, Seco V, Marco A, Rebagliato M, Grimalt JO \& Ballester F. Association between thyroid hormone levels and 4,4'-DDE concentrations in pregnant women (Valencia, Spain). Environmental Research 2009109 479-485. (doi:10.1016/j.envres.2009.02.003)

47 Pearce EN, Oken E, Gillman MW, Lee SL, Magnani B, Platek D \& Braverman LE. Association of first-trimester thyroid function test values with thyroperoxidase antibody status, smoking, and multivitamin use. Endocrine Practice 200913 33-39. (doi:10.4158/ ep.14.1.33)

48 Männistö T, Surcel HM, Ruokonen A, Vääräsmäki M, Pouta A, Bloigu A, Järvelin MR, Hartikainen AL \& Suvanto E. Early pregnancy reference intervals of thyroid hormone concentrations in a thyroid antibody-negative pregnant population. Thyroid 201121 291-298. (doi:10.1089/thy.2010.0337)

49 Pop VJ, Biondi B, Wijnen HA, Kuppens SM \& Lvader H. Maternal thyroid parameters, body mass index and subsequent weight gain during pregnancy in healthy euthyroid women. Clinical Endocrinology 201379 577-583. (doi:10.1111/cen.12177)

50 Haddow JE, Craig WY, Palomaki GE, Neveux LM, LambertMesserlian G, Canick JA, Malone FD \& D'Alton ME. Impact of adjusting for the reciprocal relationship between maternal weight and free thyroxine during early pregnancy. Thyroid 201323 225-230. (doi:10.1089/thy.2012.0440)

51 Haddow JE, Neveux LM, Palomaki GE, Lambert-Messerlian G, Malone FD \& D'Alton ME. An inverse relationship between weight and free thyroxine during early gestation among women treated for hypothyroidism. Thyroid 201525 949-953. (doi:10.1089/ thy.2015.0085)

52 Biondi B. Thyroid and obesity: an intriguing relationship. Journal of Clinical Endocrinology and Metabolism 201095 3614-3617. (doi:10.1210/jc.2010-1245)

53 Reinehr T. Obesity and thyroid function. Molecular and Cellular Endocrinology 2010316 165-171. (doi:10.1016/j.mce.2009.06.005)

54 Zimmermann-Belsing T, Brabant G, Holst JJ \& Feldt-Rasmussen U. Circulating leptin and thyroid dysfunction. European Journal of Endocrinology 2003149 257-271. (doi:10.1530/eje.0.1490257)

55 Hess SY, Zimmermann MB, Arnold M, Langhans W \& Hurrell RF. Iron deficiency anemia reduces thyroid peroxidase activity in rats. Journal of Nutrition 2002132 1951-1955.

56 Zimmermann MB, Burgi H \& Hurrell RF. Iron deficiency predicts poor maternal thyroid status during pregnancy. Journal of Clinical Endocrinology and Metabolism 200792 3436-3440. (doi:10.1210/ jc.2007-1082)

$57 \mathrm{Hu}$ X, Teng X, Zheng H, Shan Z, Li J, Jin T, Xiong C, Zhang H, Fan $C$ \& Teng W. Iron deficiency without anemia causes maternal hypothyroxinemia in pregnant rats. Nutrition Research 201434 604-612. (doi:10.1016/j.nutres.2014.06.007)

58 Yu X, Shan Z, Li C, Mao J, Wang W, Xie X, Liu A, Teng X, Zhou W, Li C et al. Iron deficiency, an independent risk factor for isolated hypothyroxinemia in pregnant and nonpregnant women of childbearing age in China. Journal of Clinical Endocrinology and Metabolism 2015100 1594-1601. (doi:10.1210/jc.2014-3887)

59 Korevaar TI, Steegers EA, de Rijke YB, Visser WE, Jaddoe VW, Visser TJ, Medici M \& Peeters RP. Placental angiogenic factors are associated with maternal thyroid function and modify hCGmediated FT4 stimulation. Journal of Clinical Endocrinology and Metabolism 2015100 E1328-E1334. (doi:10.1210/jc.2015-2553)

60 Casey BM, Dashe JS, Wells CE, McIntire DD, Byrd W, Leveno KJ \& Cunningham FG. Subclinical hypothyroidism and pregnancy outcomes. Obstetrics \& Gynecology 2005105 239-245. (doi:10.1146/ annurev.cellbio.24.110707.175418)

61 Hamm MP, Cherry NM, Martin JW, Bamforth F \& Burstyn I. The impact of isolated maternal hypothyroxinemia on perinatal morbidity. Journal of Obstetrics and Gynaecology Canada 200931 1015-1021. (doi:10.1016/S1701-2163(16)34345-6)

62 Su PY, Huang K, Hao JH, Xu YQ, Yan SQ, Li T, Xu YH \& Tao FB. Maternal thyroid function in the first twenty weeks of pregnancy and subsequent fetal and infant development: a prospective 
population-based cohort study in China. Journal of Clinical Endocrinology and Metabolism 201196 3234-3241. (doi:10.1210/ jc.2011-0274)

63 Breathnach FM, Donnelly J, Cooley SM, Geary M \& Malone FD. Subclinical hypothyroidism as a risk factor for placental abruption: evidence from a low-risk primigravid population. Australian and New Zealand Journal of Obstetrics and Gynaecology 201353 553-560. (doi:10.1111/ajo.12131)

64 Korevaar TI, Schalekamp-Timmermans S, de Rijke YB, Visser WE, Visser W, de Muinck Keizer-Schrama SM, Hofman A, Ross HA, Hooijkaas H, Tiemeier $\mathrm{H}$ et al. Hypothyroxinemia and TPO-antibody positivity are risk factors for premature delivery: the generation R study. Journal of Clinical Endocrinology and Metabolism 201398 4382-4390. (doi:10.1210/jc.2013-2855)

65 Pop VJ, Brouwers EP, Wijnen H, Oei G, Essed GG \& Vader HL. Low concentrations of maternal thyroxin during early gestation: a risk factor of breech presentation? BJOG $2004111925-930$. (doi:10.1111/j.1471-0528.2004.00213.x)

66 Männistö T, Vääräsmäki M, Pouta A, Hartikainen AL, Ruokonen A, Surcel HM, Bloigu A, Järvelin MR \& Suvanto E. Thyroid dysfunction and autoantibodies during pregnancy as predictive factors of pregnancy complications and maternal morbidity in later life. Journal of Clinical Endocrinology and Metabolism 201095 1084-1094. (doi:10.1210/jc.2009-1904)

67 Sheehan PM, Nankervis A, Araujo Junior E \& Da Silva Costa F. Maternal thyroid disease and preterm birth: systematic review and meta-analysis. Journal of Clinical Endocrinology and Metabolism 2015 100 4325-4331. (doi:10.1210/jc.2015-3074)

68 Chan S \& Boelaert K. Optimal management of hypothyroidism, hypothyroxinaemia and euthyroid TPO antibody positivity preconception and in pregnancy. Clinical Endocrinology 201582 313-326. (doi:10.1111/cen.12605)

69 Saki F, Dabbaghmanesh MH, Ghaemi SZ, Forouhari S, Ranjbar Omrani G \& Bakhshayeshkaram M. Thyroid function in pregnancy and its influences on maternal and fetal outcomes. International Journal of Endocrinology and Metabolism 201412 e19378. (doi:10.5812/ijem.19378)

70 Medici M, Korevaar TI, Schalekamp-Timmermans S, Gaillard R, de Rijke YB, Visser WE, Visser W, de Muinck Keizer-Schrama SM, Hofman A, Hooijkaas H et al. Maternal early-pregnancy thyroid function is associated with subsequent hypertensive disorders of pregnancy: the generation R study. Journal of Clinical Endocrinology and Metabolism 201499 E2591-E2598. (doi:10.1210/ jc.2014-1505)

71 Man EB, Brown JF \& Serunian SA. Maternal hypothyroxinemia: psychoneurological deficits of progeny. Annals of Clinical and Laboratory Science 199121 227-239.

72 Man EB \& Jones WS. Thyroid function in human pregnancy. V. Incidence of maternal serum low butanol-extractable iodines and of normal gestational TBG and TBPA capacities; retardation of 8-month-old infants. American Journal of Obstetrics and Gynecology 1969104 898-908. (doi:10.1016/0002-9378(69)90644-9)

73 Man EB, Jones WS, Holden RH \& Mellits ED. Thyroid function in human pregnancy. 8. Retardation of progeny aged 7 years; relationships to maternal age and maternal thyroid function. American Journal of Obstetrics and Gynecology 1971111 905-916. (doi:10.1016/0002-9378(71)90945-8)

74 Man EB \& Serunian SA. Thyroid function in human pregnancy. IX. Development or retardation of 7-year-old progeny of hypothyroxinemic women. American Journal of Obstetrics and Gynecology 1976125 949. (doi:10.1016/0002-9378(76)90494-4)

75 Finken MJ, van Eijsden M, Loomans EM, Vrijkotte TG \& Rotteveel J. Maternal hypothyroxinemia in early pregnancy predicts reduced performance in reaction time tests in 5- to 6-year-old offspring. Journal of Clinical Endocrinology and Metabolism 201398 1417-1426. (doi:10.1210/jc.2012-3389)
76 Ghassabian A, El Marroun H, Peeters RP, Jaddoe VW, Hofman A, Verhulst FC, Tiemeier H \& White T. Downstream effects of maternal hypothyroxinemia in early pregnancy: nonverbal IQ and brain morphology in school-age children. Journal of Clinical Endocrinology and Metabolism 201499 2383-2390. (doi:10.1210/jc.2013-4281)

77 Kooistra L, Crawford S, van Baar AL, Brouwers EP \& Pop VJ. Neonatal effects of maternal hypothyroxinemia during early pregnancy. Pediatrics 2006117 161-167. (doi:10.1542/peds.20050227)

78 Ohgi S, Arisawa K, Takahashi T, Kusumoto T, Goto Y, Akiyama T \& Saito H. Neonatal behavioral assessment scale as a predictor of later developmental disabilities of low birth-weight and/or premature infants. Brain and Development 200325 313-321. (doi:10.1016/ S0387-7604(02)00233-4)

79 Päkkilä F, Männistö T, Hartikainen AL, Ruokonen A, Surcel HM, Bloigu A, Vääräsmäki M, Järvelin MR, Moilanen I \& Suvanto E. Maternal and child's thyroid function and child's intellect and scholastic performance. Thyroid 201525 1363-1374. (doi:10.1089/ thy.2015.0197)

80 Pop VJ, Brouwers EP, Vader HL, Vulsma T, van Baar AL \& de Vijlder JJ. Maternal hypothyroxinaemia during early pregnancy and subsequent child development: a 3-year follow-up study. Clinical Endocrinology 200359 282-288. (doi:10.1046/j.13652265.2003.01822.x)

81 Costeira MJ, Oliveira P, Santos NC, Ares S, Saenz-Rico B, de Escobar GM \& Palha JA. Psychomotor development of children from an iodine-deficient region. Journal of Pediatrics 2011159 447-453. (doi:10.1016/j.jpeds.2011.02.034)

82 Craig WY, Allan WC, Kloza EM, Pulkkinen AJ, Waisbren S, Spratt DI, Palomaki GE, Neveux LM \& Haddow JE. Mid-gestational maternal free thyroxine concentration and offspring neurocognitive development at age two years. Journal of Clinical Endocrinology and Metabolism 201297 E22-E28. (doi:10.1210/jc.2011-1772)

83 Julvez J, Alvarez-Pedrerol M, Rebagliato M, Murcia M, Forns J, Garcia-Esteban R, Lertxundi N, Espada M, Tardón A, Riaño Galán I et al. Thyroxine levels during pregnancy in healthy women and early child neurodevelopment. Epidemiology 201324 150-157. (doi:10.1097/EDE.0b013e318276ccd3)

84 Korevaar TI, Muetzel R, Medici M, Chaker L, Jaddoe VW, de Rijke YB, Steegers EA, Visser TJ, White T, Tiemeier H et al. Association of maternal thyroid function during early pregnancy with offspring IQ and brain morphology in childhood: a population-based prospective cohort study. Lancet Diabetes \& Endocrinology 20164 35-43. (doi:10.1016/s22138587(15)00327-7)

85 Li Y, Shan Z, Teng W, Yu X, Li Y, Fan C, Teng X, Guo R, Wang H, Li J et al. Abnormalities of maternal thyroid function during pregnancy affect neuropsychological development of their children at 25-30 months. Clinical Endocrinology 201072 825-829. (doi:10.1111/ j.1365-2265.2009.03743.x)

86 Pop VJ, Kuijpens JL, van Baar AL, Verkerk G, van Son MM, de Vijlder JJ, Vulsma T, Wiersinga WM, Drexhage HA \& Vader HL. Low maternal free thyroxine concentrations during early pregnancy are associated with impaired psychomotor development in infancy. Clinical Endocrinology 199950 149-515. (doi:10.1046/j.13652265.1999.00639.x)

87 Brazelton TB \& Nugent KJ. Neonatal Behavioral Assessment Scale, vol 137, 3rd edn. London, UK: Mac Keith Press, 1995.

88 Connolly KJ, Pharoah PO \& Hetzel BS. Fetal iodine deficiency and motor performance during childhood. Lancet 19792 1149-1151. (doi:10.1016/S0140-6736(79)92382-1)

89 Hauser P, Zametkin AJ, Martinez P, Vitiello B, Matochik JA, Mixson AJ \& Weintraub BD. Attention deficit-hyperactivity disorder in people with generalized resistance to thyroid hormone. New England Journal of Medicine 199328 997-1001. (doi:10.1056/ NEJM199304083281403) 
90 McDonald MP, Wong R, Goldstein G, Weintraub B, Cheng SY \& Crawley JN. Hyperactivity and learning deficits in transgenic mice bearing a human mutant thyroid hormone beta1 receptor gene. Learning \& Memory 19985 289-301.

91 Modesto T, Tiemeier H, Peeters RP, Jaddoe VW, Hofman A, Verhulst FC \& Ghassabian A. Maternal mild thyroid hormone insufficiency in early pregnancy and attention-deficit/hyperactivity disorder symptoms in children. JAMA Pediatrics 2015169 838-845. (doi:10.1001/jamapediatrics.2015.0498)

92 Román GC, Ghassabian A, Bongers-Schokking JJ, Jaddoe VW, Hofman A, de Rijke YB, Verhulst FC \& Tiemeier H. Association of gestational maternal hypothyroxinemia and increased autism risk. Annals of Neurology 201374 733-742. (doi:10.1002/ana.23976)

93 Roman GC. Autism: transient in utero hypothyroxinemia related to maternal flavonoid ingestion during pregnancy and to other environmental antithyroid agents. Journal of the Neurological Sciences 2007262 15-26. (doi:10.1016/j.jns.2007.06.023)

94 Wegiel J, Kuchna I, Nowicki K, Imaki H, Wegiel J, Marchi E, Ma SY, Chauhan A, Chauhan V, Bobrowicz TW et al. The neuropathology of autism: defects of neurogenesis and neuronal migration, and dysplastic changes. Acta Neuropathologica 2010119 755-770. (doi:10.1007/s00401-010-0655-4)

95 van Mil NH, Steegers-Theunissen RP, Bongers-Schokking JJ, El Marroun H, Ghassabian A, Hofman A, Jaddoe VW, Visser TJ, Verhulst FC, de Rijke YB et al. Maternal hypothyroxinemia during pregnancy and growth of the fetal and infant head. Reproductive Sciences 201219 1315-1322. (doi:10.1177/1933719112450338)

96 Courchesne E, Carper R \& Akshoomoff N. Evidence of brain overgrowth in the first year of life in autism. JAMA 2003290 337-344. (doi:10.1001/jama.290.3.337)

97 Welham J, Isohanni M, Jones P \& McGrath J. The antecedents of schizophrenia: a review of birth cohort studies. Schizophrenia Bulletin 200935 603-623. (doi:10.1093/schbul/sbn084)
98 Gyllenberg D, Sourander A, Surcel HM, Hinkka-Yli-Salomaki S, McKeague IW \& Brown AS. Hypothyroxinemia during gestation and offspring schizophrenia in a national birth cohort. Biological Psychiatry 201679 962-970. (doi:10.1016/j. biopsych.2015.06.014)

99 Lazarus JH, Bestwick JP, Channon S, Paradice R, Maina A, Rees R, Chiusano E, John R, Guaraldo V, George LM et al. Antenatal thyroid screening and childhood cognitive function. New England Journal of Medicine 2012366 493-501. (doi:10.1056/ NEJMoa1106104)

100 Zoeller RT \& Rovet J. Timing of thyroid hormone action in the developing brain: clinical observations and experimental findings. Journal of Neuroendocrinology 200416 809-818. (doi:10.1111/j.13652826.2004.01243.x)

101 Casey BM. Effect of treatment of maternal subclinical hypothyroidism or hypothyroxinemia on IQ in offspring. Abstract S2. American Journal of Obstetrics \& Gynecology 2015214 S2. (doi:10.1016/j.ajog.2015.10.023)

102 World Health Organization, UNICEF \& International Council for the Control of Iodine Deficiency Disorders. Assessment of Iodine Deficiency Disorders and Monitoring Their Elimination, 3rd edn. Geneva, Switzerland: WHO, 2007.

103 Moleti M, Trimarchi F, Tortorella G, Candia Longo A, Giorgianni G, Sturniolo G, Alibrandi A \& Vermiglio F. Effects of maternal iodine nutrition and thyroid status on cognitive development in offspring: a pilot study. Thyroid 201626 296-305. (doi:10.1089/thy.2015.0336)

104 Beard JL, Borel MJ \& Derr J. Impaired thermoregulation and thyroid function in iron-deficiency anemia. American Journal of Clinical Nutrition 199052 813-819.

105 Hess SY \& Zimmermann MB. The effect of micronutrient deficiencies on iodine nutrition and thyroid metabolism. International Journal for Vitamin and Nutrition Research 200474 103-115. (doi:10.1024/03009831.74.2.103)

Received 11 August 2015

Revised version received 10 February 2016

Accepted 15 February 2016 